(c) 1981. The Genetical Society of Great Britain

\title{
THE WIDTH OF THE HYBRID ZONE IN CALEDIA CAPTIVA
}

\author{
N. H. BARTON \\ Department of Genetics, Downing Street, Cambridge, CB2 3EH
}

Received 21.iv.81

THE grasshopper Caledia captiva contains several chromosomal races. Two of these, the Torresian and the Moreton, are distinguished by pericentric inversions affecting all eleven pairs of autosomes and the sex chromosome, which transform the acrocentric Torresian karyotype into the metacentric Moreton type (Shaw, 1976; Moran and Shaw, 1977; Moran, 1978). These races are also distinguished by their distributions of heterochromatin, and by substitutions at five enzyme loci (Shaw et al., 1979; Moran et al., 1980). In laboratory crosses, there is severe hybrid breakdown during embryogenesis in the F2 and backcross, perhaps caused by these differences, or perhaps by others (Shaw and Wilkinson, 1980). The races meet in a hybrid zone which runs for $225 \mathrm{~km}$ through S.E. Queensland, and it has been proposed that the two types remain separated by this zone because of the reduced hybrid fitness (Moran, 1979; Shaw et al., 1980).

In this note, I will discuss just one aspect of this hybrid zone-the precise relation between its width and the fitness of hybrids. The work on Caledia raises many other intriguing questions; for example, there is markedly asymmetrical introgression of the Torresian chromosomes into the Moreton race, which led Moran (1979) to suggest that the Moreton race is moving forwards. However, Moran points out that any such movement would soon be halted by gradients in the environment and in population structure; this is supported by theoretical analysis (Barton, 1979a). In any case, the movement of a hybrid zone does not directly affect its width, and so this aspect, though important, can be set aside for present purposes.

Most of the karyotypic change occurs within $200 \mathrm{~m}$; more exactly, we can measure cline width by the inverse of the maximum slope (May et al., 1975 ), giving a value of $\sim 350 \mathrm{~m}$, varying somewhat between chromosomes. This seems narrow relative to the range of the species, but is much wider than the individual dispersal range, stated by Shaw et al. (1980) as only 5-10 metres over a two week mark-release-recapture experiment. Indeed, in several other hybrid zones the width is also greater than the likely dispersal range; in Mus musculus/domesticus, the cline is at least $20 \mathrm{~km}$ wide (Hunt and Selander, 1973); in the snail Cerion abacoense/bendalli, the width is $\sim 1 \mathrm{~km}$ compared to a measured lifetime dispersal of $\sim 3 \mathrm{~m}$ (Woodruff and Gould, 1980); in the frog Pseudophryne bibroni/semimarmorata, the width of morphological change is $\sim 3 \mathrm{~km}$ (McDonnell et al., 1978); and in the grasshopper Podisma pedestris, the cline in chromosome type is $\sim 800 \mathrm{~m}$ wide, and the cline in hybrid inviability is $\sim 350 \mathrm{~m}$ wide, compared with a lifetime dispersal of $\sim 20 \mathrm{~m}$ (Hewitt and Barton, 1981; Barton and Hewitt, 1981). Now, if, as seems likely, these clines are maintained by a balance between dispersal and hybrid unfitness, a substan- 
tial and robust body of theory shows that the ratio between width and dispersal is a measure of the strength of the selection acting on each locus involved (e.g., Endler, 1977). Hence, the above observations imply that the selection acting must be weak. However, in Caledia, laboratory crosses have shown that the selection acting against hybrids is extremely strong; the hybrid zone is paradoxically wide.

Moran (1979) has set out a model describing the frequencies of the karyotypes through the first two generations of hybridisation. However, since this model cannot be carried further without defining the fitness of multiple backcross derivatives, and does not explicitly take dispersal into account, it is not adequate to describe the equilibrium structure of the zone. So, to clarify the paradox of the width of the Caledia cline, I will briefly describe the consequences of a mathematical model based on the mechanism of hybrid breakdown proposed by Shaw and his co-workers. The model is constrained by the observation that $\mathrm{F} 1$ hybrids are essentially normal, but F2's die during embryogenesis. Backcrosses to either parental race have viability varying between 0 and 50 per cent. (This summary neglects the subtleties of the results presented in Shaw et al. (1980), but to include these would complicate matters needlessly.) The breakdown is not due to meiotic problems; the chromosomes segregate normally. It is proposed instead that recombination produces deleterious gametes. This could be because the two races have fixed different co-adapted sets of alleles, which only work well with each other. It could also be because the loss of fitness is caused by the change in recombination pattern in chromosomal heterozygotes, which have chiasmata in parts of the chromosome which are normally left intact. If there are co-adapted sets which are polymorphic within each race, these might be broken up by the abnormal chiasmata in hybrids, again reducing fitness. Shaw et al. prefer this latter hypothesis, and so although the exact cause of hybrid inviability should make little difference to the results, the model set out below will follow their preference.

Let there be three types of gamete, with frequencies, $m, t$ and $r ; \mathrm{M}$ and $\mathrm{T}$ represent pure Moreton and Torresian gametes, whilst $\mathrm{R}$ gametes are formed by recombination between the two. Since all F2 offspring die, we will suppose that recombination is certain, so that $M / T$ F1's produce only $\mathbf{R}$ gametes, and that $\mathrm{R} / \mathrm{R}$ embryos have fitness $(1-l)$. In backcrosses, there is partial inviability; so, let the fitness of $\mathrm{R} / \mathrm{M}, \mathrm{R} / \mathrm{T}$ be $(1-h)$. Recombination from $R / M$ to $R / R$ types has been neglected; if only two elements are involved, this would be impossible, whilst if more were involved, selection against hybrids would be raised by the increased frequency of $\mathbf{R}$ gametes, and the cline would be narrower. Another simplification is that all " $R$ " types are equivalent. Thus, the selection scheme is described by the parameters $h$ and $l$.

Dispersal may be described by a stepping stone model; the results here come from a model in which demes exchange half their population with each neighbour every generation. However, the pattern of exchange affects the cline shape very little, provided the variance of gene flow, $\sigma^{2}$, is constant.

By iterating until equilibrium, one can find the relation between the selection pressures in backcross and F2, and the cline width (fig. 1). If selection were acting at a single "locus" of the type described above, $l$ would have to be $\sim 1$, and $h>0.5$ to account for the viabilities of the 


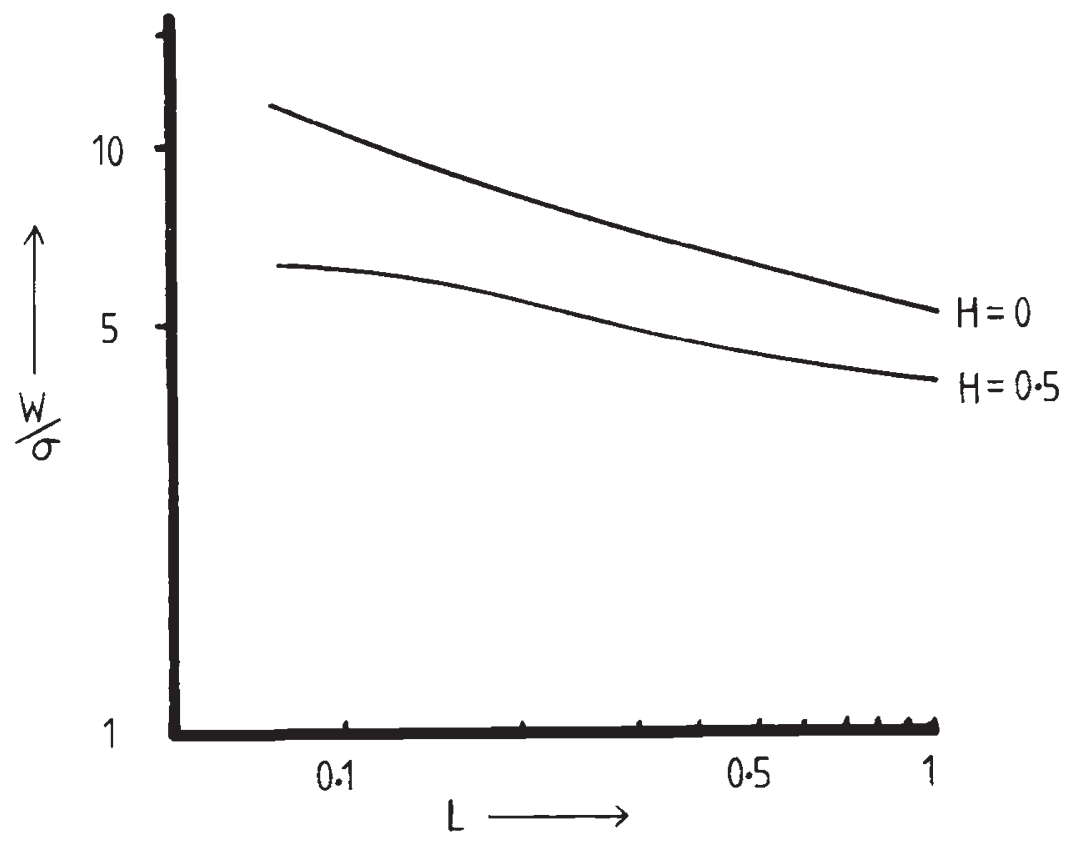

FIG. 1.-The width of the cline produced by the model described in the text, measured in dispersal distances $(W / \sigma)$, for various values of the fitness parameters $l$ and $h$.

laboratory crosses. Hence, the cline could be at most 3.9 dispersal distances $(\sigma)$ across. It would be more realistic to suppose that selection acts on the twelve chromosomes independently; the selection on each could be much weaker, since the hybrid unfitness is due to the cumulative effects of all the chromosomes. The F2 fitness must be less than, say, 3 per cent $=$ $(1-l)^{12}$, and so $l$ is at least 25 per cent. Similarly, $h$ is at least 5 per cent, and so the width must be less than $7 \cdot 3 \sigma$. So, spreading the selection out over 12 loci doesn't help much. One might get a greater width by allowing non-multiplicative fitness interactions between chromosomes. The cline width is determined by the marginal fitness differences at each locus, whilst the F2 fitness is determined by the combination of all these differences, so that the relation between width and hybrid fitness depends on the way the loci interact. However, these non-linearities would have to be very strong to raise the width substantially (see Barton and Hewitt, 1981).

Of course, one could continue postulating more and more loci, with weaker and weaker selection on each. However, this solution is constrained by the production of linkage disequilibrium between the loci, which would narrow the cline (Slatkin, 1975). One might argue that since the cline appears to be many dispersal distances across $(W \gg \sigma)$, the disequilibrium between two loci, with frequency gradients $(1 / W)$, produced by the mixing of dissimilar populations is $\leqq\left(\sigma^{2} / r w^{2}\right)$ (from Barton, 1979b). This disequilibrium should be negligible for $r \sim 0.5$. However, there is in fact strong disequilibrium between the various chromosome rearrangements; most pair-wise $\chi^{2}$ tests are significant on the Torresian side of the zone, 
and there is a substantial excess of "F1" multiply heterozygous karyotypes throughout the zone. Selection must therefore act as if on a single locus, and so the cline should only be a few dispersal distances across.

To sum up, the Caledia hybrid zone involves severe selection and strong disequilibrium, and yet it seems wide relative to the measured dispersal abilities of the organism. One can only hope that continued analysis of this system will resolve the puzzle.

\section{REFERENCES}

BARTON, N. H. 1979a. The dynamics of hybrid zones. Heredity, 43, 341-359.

BARTON, N. H. 1979b. Gene flow past a cline. Heredity, 43, 333-340.

BARTON, N. H., AND HEWITT, G. M. 1981. The genetic basis of hybrid inviability in the grasshopper Podisma pedestris. Ms. submitted to Heredity.

ENDLER, J. A. 1977. Geographic variation, speciation and clines. Princeton Univ. Press, Princeton.

HEWITT, G. M., AND BARTON, N. H. 1981. The structure and maintenance of hybrid zones as exemplified by Podisma pedestris. In Royal Entomological Society Symp. X. "Insect Cytogenetics", eds. R. L. Blackman, G. M. Hewitt, and M. Ashburner, pp. 149-169, Blackwell, Oxford.

HUNT, W. G., AND SELANDER, R. K. 1973. Biochemical genetics of hybridisation in European house mice. Heredity, 31, 11-33.

McDONNELl, L. J., GARTSIDE, D. F., AND LitTLEJOHN, M. J. 1978. Analysis of a narrow hybrid zone between two species of Pseudophryne (Anura: Leptodactylidae) in S.E. Australia. Evolution, 32, 602-612.

MAY, R. M., ENDLER, J. A., AND McMURTRIE, R. E. 1975. Gene frequency clines in the presence of selection opposed by gene flow. Amer. Nat., 109, 659-676.

MORAN, C. 1978. Population studies of Caledia captiva (Orthiptera: Acridinae) in south-east Queensland. Ph.D. Thesis, Australian National University, Canberra.

MORAN, C. 1979. The structure of the hybrid zone in Caledia captiva. Heredity, 42, 13-32.

MORAN, C., AND SHAW, D. D. 1977. Population cytogenetics of the genus Caledia (Orthoptera: Acridinae). III. Chromosomal polymorphism, racial parapatry, and introgression. Chromosoma (Berl), 63, 181-204.

MORAN, C., WILKINSON, P., AND SHAW, D. D. 1980. Allozyme variation across a narrow hybrid zone in the grasshopper Caledia captiva. Heredity, 44, 69-81.

SHAW, D. D. 1976. Population cytogenetics of the genus Caledia (Orthoptera: Acridinae). I. Inter- and intra-specific karyotype diversity. Chromosoma (Berl), 54, 221-243.

SHAW, D. D., AND WILKINSON, P. 1980. Chromosome differentiation, hybrid breakdown and the maintenance of a narrow hybrid zone in Caledia. Chromosoma (Berl), 80, 1-31.

SHAW, D. D., MORAN, C., AND WILKINSON, P. 1980. The mechanism of speciation in the genus Caledia. In Royal Entomological Society Symp. X, "Insect Cytogenetics", eds. R. L. Blackman, G. M. Hewitt, and M. Ashburner, pp. 171-194. Blackwell, Oxford.

SHAW, D. D., WILKINSON, P., AND MORAN, C. 1979. A comparison of chromosomal and allozymic variation across a narrow hybrid zone in the grasshopper Caledia captiva. Chromosoma (Berl), 75, 333-351.

SLATKIN, M. 1975. Gene flow and selection in a two locus system. Genetics, 75, 787-802. WOODRUFF, D. S., AND GOULD, S. J. 1980. Geographic differentiation and speciation in Cerion: a preliminary discussion of patterns and processes. Biol. J. Linn. Soc., 14, 389-416. 